\title{
THE CIPA DATABASE FOR SAVING THE HERITAGE OF SYRIA
}

\author{
Minna Silver, ${ }^{\mathrm{a},{ }^{*}}$, Fulvio Rinaudo $^{\mathrm{b}}$, Emanuele Morezzi $^{\mathrm{b}}$, Francesca Quenda $^{\mathrm{b}}$, Maria Laura Moretti ${ }^{\mathrm{b}}$ \\ ${ }^{a}$ University of Oulu, Finland - minna.silver@helsinki.fi \\ b Politecnico di Torino, Italy- fulvio.rinaudo@polito.it, emanuele.morezzi@polito.it, francesca.quenda@polito.it, \\ marialaura.moretti@studenti.polito.it
}

Comission V, Special Session 1 - CIPA

KEY WORDS: Cultural Heritage, Database, Documentation, Data standards, GIS

CIPA is contributing with its technical knowledge in saving the heritage of Syria by constructing an open access database based on the data that the CIPA members have collected during various projects in Syria over the years before the civil war in the country broke out in 2011. In this way we wish to support the protection and preservation of the environment, sites, monuments, and artefacts and the memory of the cultural region that has been crucial for the human past and the emergence of civilizations. Apart from the countless human atrocities and loss, damage, destruction and looting of the cultural heritage have taken place in a large scale. The CIPA's initiative is one of the various international projects that have been set up after the conflict started. The Directorate-General of the Antiquities and Museums (DGAM) of Syria as well as UNESCO with its various sub-organizations have been central in facing the challenges during the war. Digital data capture, storage, use and dissemination are in the heart of CIPA's strategies in recording and documenting cultural heritage, also in Syria. It goes without saying that for the conservation and restoration work the high quality data providing metric information is of utmost importance.

\section{INTRODUCTION}

CIPA, the joint organization of ICOMOS (International Council on Monuments and Sites under UNESCO) and ISPRS (International Society of Photogrammetry and Remote Sensing) is a scientific commission devoted, as main focus, to the recording and documentation of tangible cultural heritage including cultural landscapes, archaeological, architectural and artistic data. It develops and uses the best technical equipment, methods and practices in documenting the heritage. CIPA's current aim is to set up an open access database, a platform for information sharing, focused on sites and monuments to protect and preserve the cultural heritage of Syria. CIPA's asset is the expertise of high-tech data capture, storage, use and dissemination. The data used by CIPA are metric data based on image-based or range-based data capture, analysis and visualization. The purpose is to provide data that can be digitally used and shared. The data can serve institutions, organizations, cultural management stakeholders, individual researchers and private enthusiasts.

Syria is one of the cradles of human civilization in the Near East covering parts of the Levant and Mesopotamia, being in the continental crossroads of Africa, Asia and Europe. It was a bridge for the early human movement in the Palaeolithic era. For example, the tools from El Kowm basin belonging to the so-called Pebble Culture are dating 1,8 million years back (Le Tensorer et al., 2015). At Abu Hureyra in the Lake Assad area on the Euphrates evidence of the earliest agricultural initiatives from ca. 9000 BC have been discovered (Moore et al., 2000), and on the coastal areas some of the first signs of alphabetical writing system have been traced at the site of Ugarit-Ras Shamra (Schniedewind and Hunt, 2007).

\section{THE SITUATION OF SYRIA}

Since the Arab Spring of 2011 and the start of the Syrian civil war, apart from the countless human sufferings and loss, the cultural heritage of the region has been continuously and speedily damaged and destroyed (Fig. 1.). Such sites as Aleppo and Palmyra, also belonging to the World Heritage Sites defined by UNESCO, have faced total destruction of monuments during the conflict. The intentional destruction has been partly led by ISIS/ISIL (the Islamic State of Iraq and Syria) at Palmyra that was captured by the Islamic militants in May 2015 (Lönnqvist, 2015a and 2015b).

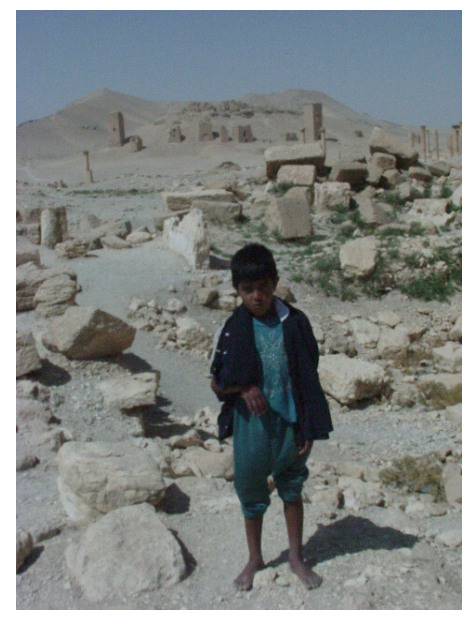

Figure 1. A Syrian child photographed with a first generation digital camera in the midst of the Palmyra ruins in 2000 before the conflict. Photo: SYGIS, the Finnish project in Syria.

But also the trafficking of illicit antiquities out of Syria has been growing and drying the artery reflecting the past lives in the human made artefacts and traditions that belong to the cultural patrimony of the people of the area. Valuable initiatives and more coordinated efforts are taking place to plan how to collect data and share it for the purpose of the heritage preservation. There are scientific requirements and standards for the use of 
the data and material from the conservation point of view that need to be assessed.

\section{CIPA AMONG THE CULTURAL HERITAGE INITIATIVES OF SYRIA}

Some members of the CIPA executive board, who personally have worked in various projects in Syria, have interesting data regarding the recorded and documented tangible heritage of the region, especially from the Aleppo and Palmyra areas. This data is serving as a basis for our initiative that was decided in the CIPA executive board meeting in Riva del Garda, Italy, in 2014.

However, as mentioned, CIPA is a joint organisation of ICOMOS and ISPRS and the available data mainly concerns location information, sites and monuments, and the information of the data concerning movable artefacts associated with the sites under CIPA's scope is limited. That data belongs to the field of expertise of ICCROM (International Centre for the Study of the Preservation and Restoration of Cultural Property, www.iccrom.org) and ICOM (the International Council of Museums, www.icom.museum) and may only be referred to or supplied when available and applicable. On the other hand, our data is important to any study of artefacts and their provenances. This is to be taken into account in the case of the increased trafficking of looted antiquities out from Syria during the conflict.

The database design with the graphic interface of the CIPA project has been presented in The $10^{\text {th }}$ International Conference on Archaeology of the Ancient Near East (ICAANE), for the first time, in a specific CIPA Workshop on Saving the Cultural Heritage of Syria that is taking place in Vienna in April 2016 (www.orea.oaw.ac.at./10icaane.html, Rinaudo and Silver, 2016) in order to get some feedback of its structure and developing it further. After the meeting and fixing the goal with the executive board of CIPA the project will aim designing the database from the initial phase further. A survey of the existing datasets and databases concerning the Syrian heritage built up by other organizations is acknowledged in the construction of the CIPA inventory. Already accessible data will not need to be duplicated. A link is provided to other datasets and databases offering existing material or information when such knowledge is available.

The storages, archives, museums, datasets and databases of DGAM (Directorate-General of Antiquities and Museums of Syria) are central in saving the cultural heritage of Syria. Apart from the initiatives of UNESCO (the United Nation, Organization for Education, Science and Culture: UNESCO Observatory of Syrian Cultural Heritage and the project Safeguarding Syrian Heritage at www.unesco.org), ICOMOS and ICORP (International Committee on Risk Preparedness, www.icorp.icomos.org) organizations under UNESCO are specialized in safeguarding the cultural sites, the latter especially in the case of catastrophes. ICCROM and ICOM under UNESCO are active in conservation, restoration as well as storing artefacts. UNITAR (www.unitar.org) under UN with its UNOSAT programme has collected satellite data of the damage at heritage sites in Syria. The International Committee of the Blue Shield (ICBS, www.ancbs.org) has taken special actions in protecting and preserving the heritage in conflict areas like Syria.

ASOR Cultural Heritage Initiatives (American Schools of Oriental Research, www.asor-syrianheritage.org) are also active in the field. CyArk is documenting digitally at-risk heritage sites in Syria in co-operation with ICOMOS (www.cyark.org). The World Monuments Fund is also supporting the site preservation in Syria (https://www.wmf.org/project/culturalheritage-sites-syria). SHIRIN International (Syrian Heritage in Danger: an International Research Initiative and Network at www.shirin-international.org) and EAMENA (Endangered Archaeology in the Near East and North Africa at Oxford University, www.eamena.arch.ox.ac.uk) are organisations working to save the Syrian heritage based in Europe.

In co-operation with UNESCO 3D cameras have been provided by British funds and coordinated by the Institute for Digital Archaeology (www.digitalarchaeology.org.uk) for locals in Syria to document endangered sites. People on the ground in Syria have been involved in sharing information by images and videos during the armed conflict. Antiquities Coalition (https://antiquitiescoalition.org) has especially been fighting against trafficking of the looted artefacts.

Manar al-Athar is a free online multi-media source with a photoarchive at Oxford University (www.manar-alathar.ox.ac.uk) that includes data from Syria. SYRHER (Syrian Heritage Archive Project, Germany, www.syrian-heritage.org) and the Aleppo Project at Center for Conflict, Negotiation and Recovery at Central European University, Hungary, are also contributing in the preservation work. Some databases use ARCHES platform developed by the Getty Conservation Institute (www.getty.edu).

In addition, APSA (the Association for the Protection of Syrian Archaeology, www.apsa2011.com) and the Heritage for Peace organization (www.heritageforpeace.org) should be mentioned as actively participating in sharing information of the situation with the cultural heritage in Syria

\section{THE CIPA PROJECT}

\subsection{The Aims and Strategy}

It is well known that in protection and preservation of tangible cultural heritage each recording and documentation action needs to be planned and oriented by considering the specific use of the documentation. However, CIPA is not involved in targeted recording and documentation in Syria at the moment but will be first primarily using the existing data held by the CIPA members (images, metric and historical records, like maps, drawings and textual descriptions, as well as reports of archaeological studies) and to organize the data into a database structure useful to the conservators and restorers beside archaeologists and architects.

The main aim of the CIPA project is concentrating on a specific goal: to provide the restorers and conservators with all the available data that CIPA has and provide links which will allow the design of future actions. The second aim of the CIPA effort is to collect the existing data from other stakeholders to offer the possibility to transmit worldwide knowledge of this universal patrimony. In the following paragraph the first steps of the CIPA project will be described as it was conceived by a group in which Archaeology, Architecture, Conservation, and Geomatics expertise were present. In the long run the project wants to contribute to the safeguarding of the heritage by considering not only the collection of existing records but by inserting them into a more complete approach which is oriented to plan a strategy for a real preservation of the data. 
The first step of the CIPA project is the data collection, and it is organized by following two different strategies. The first action is the description (by using the metadata structure described in the following paragraphs) of the data collected from the CIPA members, and in future the data collected from other providers. The second step is to attach the metadata for the data and to store the accepted data to allow the downloading it to the interested parties. All the collected data will be described in a synthetic way. At the end as the third step, it will be possible to design a database structure to be implemented inside a GIS (Geographic Information Systems) platform (Fig. 2) (see, e.g., Ardissone and Rinaudo, 2005, Lönnqvist and Stefanakis, 2009) with open access possibilities.

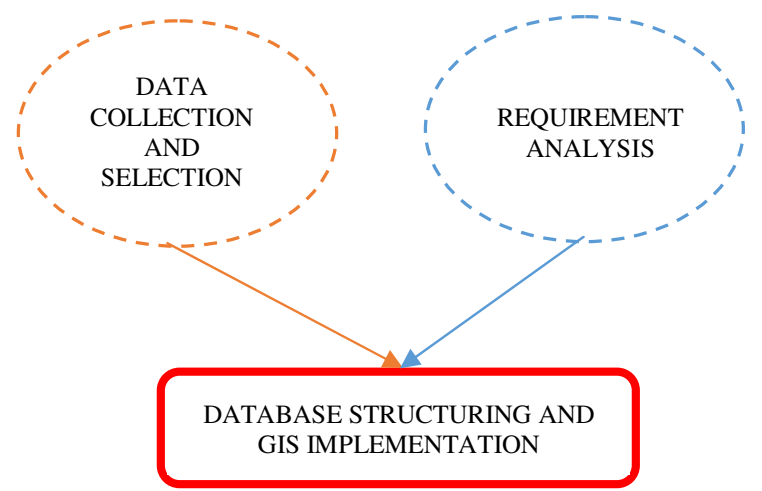

Figure 2. The three steps of the CIPA project

\subsection{The Data Structure and Data Archiving}

The data to be collected, saved and disseminated have been conceived as primary data and elaborated data.

Primary data (Fig. 3) are essentially images and videos. Images are split into two different categories: descriptive images and metric images. Descriptive images come basically from photographic surveys made in the past by specialists but also tourist type of documentation at sites at different times. Metric images are classified by considering the medium scales into terrestrial, aerial and/or satellite images.

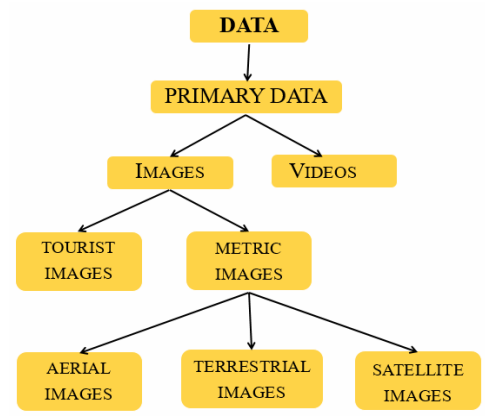

Figure 3. Primary data classifications

Elaborated data (Fig. 4) concerns 2D maps, drawings, 3D models and reports. It may include ranged-based data, like point clouds. 2D maps will be subdivided into cartographic products, excavation plans and architectural scale drawings. 3D models and reports will be organized by considering different scales: environment and/or landscape, urban scale or architectural objects.

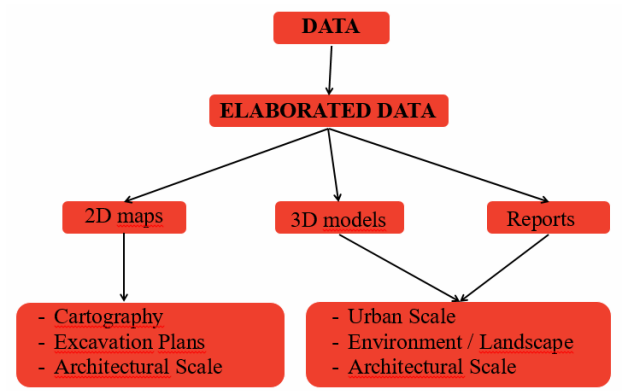

Figure 4. Elaborated data classifications

\subsection{Setting Up a Graphic Interface for the Data}

As CIPA's aim is to collect and share the data through an open access digital platform on the internet and develop the database further, a website is conceived as an efficient tool (Fig. 8).

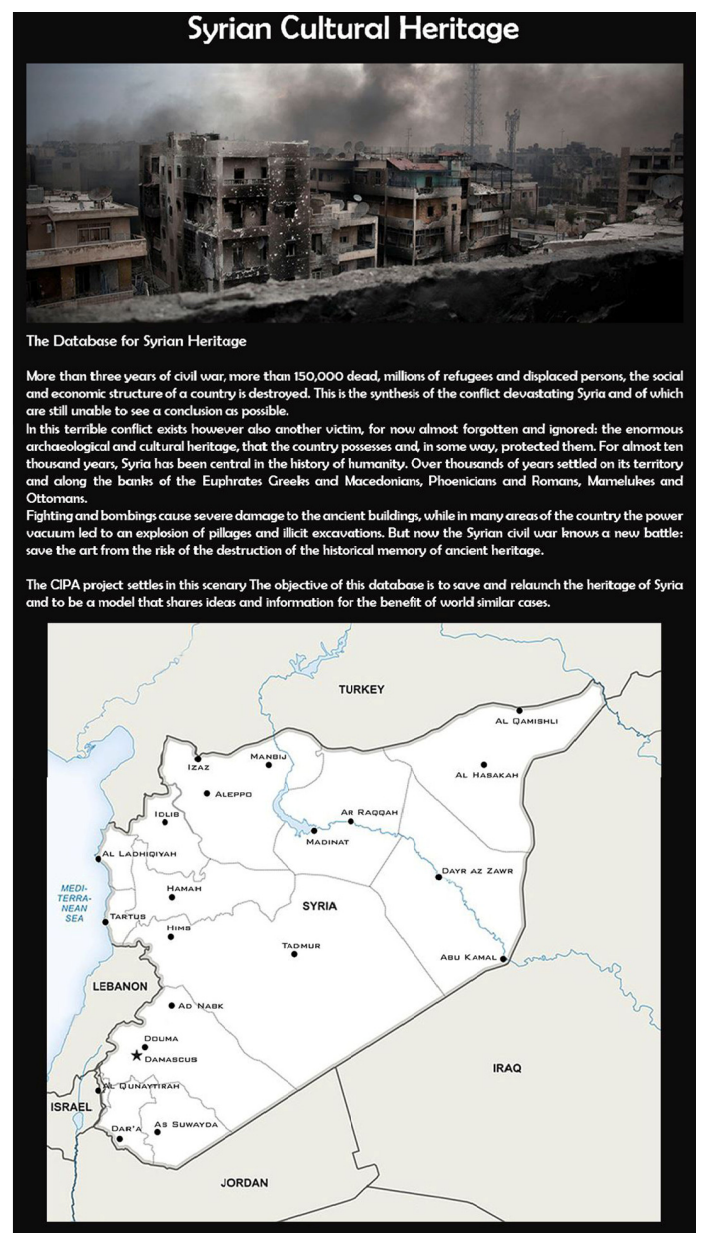

Figure 5. The CIPA website interface

The website is designed in the simplest possible way to allow an easy access to the stored and connected information and to ease the upload of new set of data by all the interested people. The main page offers the territorial map of Syria (Fig. 5) as it existed before the civil war broke out and where all the locations with available data will be underlined. This basic map 
of Syria with its governorates and centres will be in due course linked with the Google Earth map that provides the inter-active locations of places and sites. The question of the site names in main languages and spellings are taken into account: beside English transliterated Arabic, French, German and Italian can be applied.

By clicking on specific locations, the visitor can see the type of accessible data by following the conceived structure of the data (see Figs. 3 and 4). The first possibility to access the data is by quering the data according to the origin (the CIPA data or external data, Fig. 6). The second possibility is to access the data by considering the type of the data (images, videos, reports, Fig. 7). Both possibilities open the access to the stored and shared material with the visualisation of the related metadata.

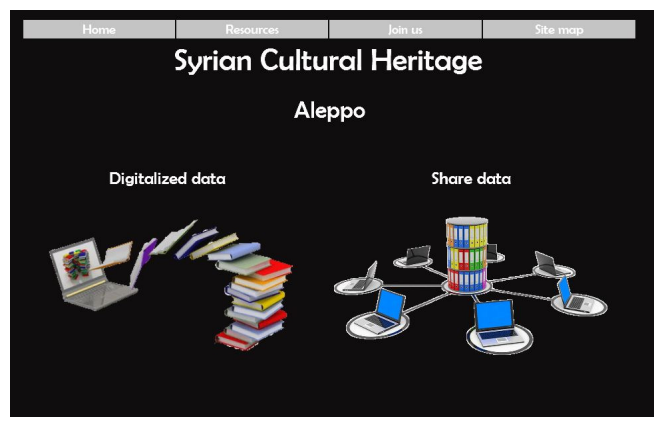

Figure 6. Selection between the CIPA data and external data

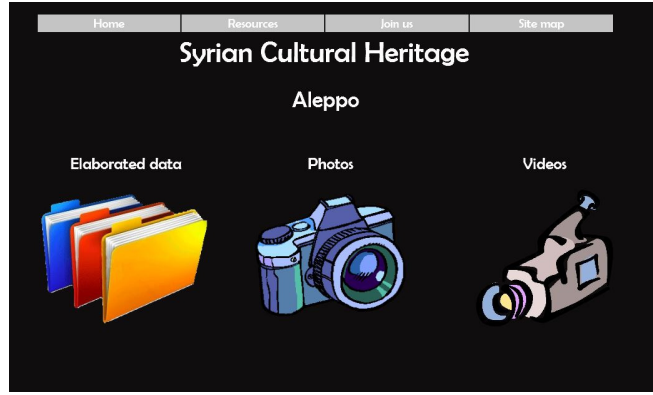

Figure 7. Collecting the elaborated data

\subsection{The Data Collection and Core Metadata}

As previously mentioned, the data to be archived in the CIPA server is based on the CIPA members' data acquisition and collection and later the acquisition as a voluntary action is proposed by the website, where people are invited to submit data. They can follow a simple interface (Fig, 8) on which they are invited to describe the uploaded data by a short set of metadata. The data collectable by following the already presented scheme (Fig. 2) could not create an understandable dataset for the aims of the project without a preliminary classification by using a simple set of metadata

It is well known that in a rigorous database design the metadata structure is essential to understand the real content of the data themselves. Our proposal is to start with a simple metadata structure in order to be able to clarify the real information contents of the collected data and to postpone a more rigorous attribute and metadata structures in the third step of the project when a real database for a GIS platform will be realized.
By considering the different kinds of data the CIPA project wants to manage the metadata that has been conceived as a shell structure where, beside a set of common metadata for all the possible achievable data, specific metadata has been selected for each kind of interesting data. The following steps drive the visitor to select various data by considering the year of the data production, the author, the data provider and the specific object (Fig. 8). Without considering the kind of data to be acquired, the following set of metadata has been established:

1. SITE NAME. By considering the consistency of the cultural heritage in Syria, the name of the site is the first location key for each data. Several sites are specified by various experts (archaeologists, historians, conservators, etc.) in different ways (e.g. the site of Palmyra as Tadmor, Tadmur, Palmyra, Palmyre, Palmira, etc.). In order to avoid this problem, in the first step of the classification the data provider is asked to indicate the exact place by using a Google Earth map interface. The choice to avoid the use of the cartographic coordinates is due to the fact that it is difficult for non-specialists to deal with cartographic problems to clearly identify the reference and coordinate systems.

2 .

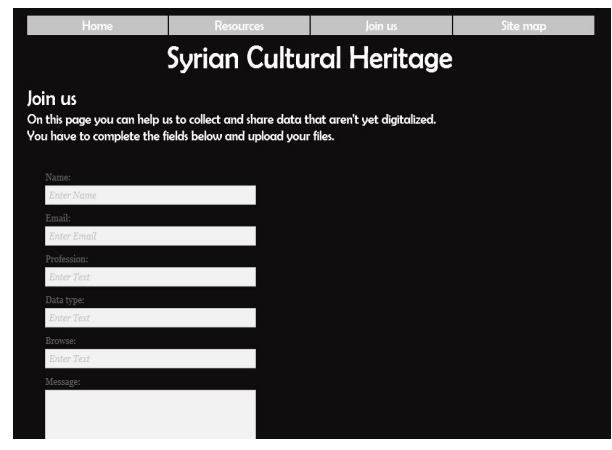

Figure 8 . The site of data collection

3. OBJECT. This information is asked from the data provider to indicate in a general way if the data refers to a landscape, a site, a building, an artefact by indicating also whether the object of the data is still existing or not.

4. CREATION DATE. This field aims to define when the data was acquired, and to be specified also by indicating just the year in case no more information is available.

5. AUTHOR. This field requires the name and affiliation of the data producer that can be different from the one of the data provider. This information will be used to check possible copyright conflicts by publishing the data.

6. DATA SUPPLIER is the information about the person/people who is/are uploading the data useful to obtain wider information in the case of necessity.

7. FILE FORMAT. The data have to be uploaded in one of the most diffused and open format like "pdf" and "3D pdf" for text and 3D models, "dxf" for drawings and "JPEG" or "TIFF" for images.

8. DOWNLOAD. This last information is the one required to understand if the data can be uploaded onto the CIPA server and then downloaded by interested people or can just be viewed on the website or if the possibility to download the data is limited by payments and/or specific authorization of the data owner.

During each upload a free text field will be provided to allow the data supplier to add any other information useful to better understand the information content. 


\subsection{The Data Evaluation and Data Standards}

By considering the importance of the first steps, the web site has to be managed by a team of experts with skills in metric survey, archaeology, architecture and conservation. All the uploaded data has to be checked in terms of readability and completeness of the metadata information. The same team will be responsible also for checking similar initiatives and providing the necessary metadata structure for those data not directly inserted inside the CIPA project.

The collection of the existing data is forced to face specific problems about the knowledge of the quality of the collectable data in terms of significance, accuracy (not only metric but also semantic), and therefore a preliminary action of collection, analysis and classification is needed (Fig. 2). Obviously in the case of data offered by the other initiatives the set of the common metadata will be provided by the manager of the CIPA initiative by reading the data directly from the websites or by asking the information from the responsible persons of single projects.

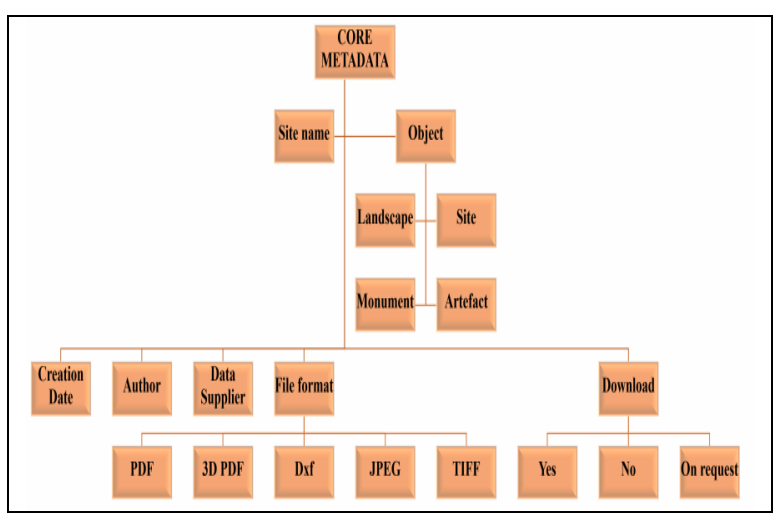

Figure 9. Core metadata structure

The above proposed preliminary scheme for the core metadata (Fig. 9) will allow the first recognition of the really usable data. For each category of data, specific metadata have been defined in order to have better knowledge about the informative content of them. If some of the single metadata is not defined by the provider, the data will be directly inspected by the manager of the CIPA project in order to allow the introduction inside the future GIS structure. The basic information following the core data standards, such as a site and its location as defined in the CIDOC data standard (www.cidoc-crm.org) and the CIPA RecorDIM data standard task group specifications are applied in evaluation of the data. However, as far as the CIDOC is concerned some additions will be made in collecting environmental and landscape data associated with the site/s and monuments when available.

The exact location of a site is a primary parameter in queries and the basic feature in data standards to be taken into account in any aim to protect and preserve a site, or a monument needed also for its future conservation and eventual restoration. Without coordinate information the exact locations of sites with their street addresses and monuments may be lost for ever. This is an issue in the areas that have been under conflicts or faced natural disasters. Such transformations can change the landscape and site structures with streets and architectural features.
It therefore needs to be kept in mind that the street addresses are not eternal and notes of directions without global references, like coordinates, are data that can totally vanish. The map location on Google Earth with the used coordinates and local grid systems can provide an initial basis for the site assessment, but the UTM is the preferred coordinate system and will be applied, when such data is available, associated with sites and monuments. The lack of coordinate information may also make a future archaeological assessment and study of the site after the conflict difficult. It also affects to the extent of the site and its buffer zones.

But the reasons why also the environment and landscape aspects are applied is the modern approach in which the sites and monuments are to be understood in their context or setting (cf. Vita-Finzi, 1978). The environmental and landscape data provides the means to understand the site development and effects of the environment. Apart from old drawings, old photographs can be used in studying the evolution of landscapes, sites and monuments (see Figs. 13, 16, 18, 19).

The date of the data is essential in understanding the development of sites and structures, and the CIDOC standard is applied in associating the date information. This also is an aspect that needs to be taken into account in data evaluation. In addition, references to the events like the field work are provided when available. For the elaborated data such as $2 \mathrm{D}$ drawings and 3D models a nominal scale would need to be defined by the data supplier and if the data are stored in a reduced scale or in 1:1 scale. However, all data, even without scale, may turn to be important, if nothing else is available.

The specific information needed for photographs and images concerns the used camera and focal length. (For old and tourist photographs that information may, however, be difficult to achieve and then need to be left out.) In addition, for metric images the availability of a calibration certificate and a scale may allow resulting in a $3 \mathrm{D}$ model. An indication of the overlaps of the images and the taken distance will be asked for. For satellite images the satellite system which provided the images is an important data to be known. By considering the fact that in some cases not only images in the visible spectrum have been used but also the data supplier should indicate if the images are multispectral data. The information of the used bands during the recording of the images is also needed.

\section{ALEPPO AND PALMYRA AS CIPA CASE SITES}

As previously mentioned, the destruction of architectural and archaeological heritage in Syria has especially taken place in a large scale in Aleppo and Palmyra, both belonging to the UNESCO's World Heritage Sites. The CIPA members, who had acquired data especially in those cities before the civil war broke out, are providing data for the CIPA project. This data will be inserted into the CIPA server. In the following paragraphs we provide some initial examples.

\subsection{Aleppo: the Citadel and the Great Mosque}

Aleppo is the second largest city of Syria, but the whole city has heavily been damaged during the civil war. The old covered market, the souq, was one of the first targets of destruction. The APSA organisation is paying special attention to the post-war reconstruction of Aleppo (Ali, 2016). The Medieval citadel of Aleppo (Figs. 11, 12) is an area that encloses the early urban 
layers of the city, a tell, that was known as the centre of the kingdom of Yamhad in the Middle Bronze Age (Lönnqvist, 2000). The area has faced destruction including the walls and the main gate.

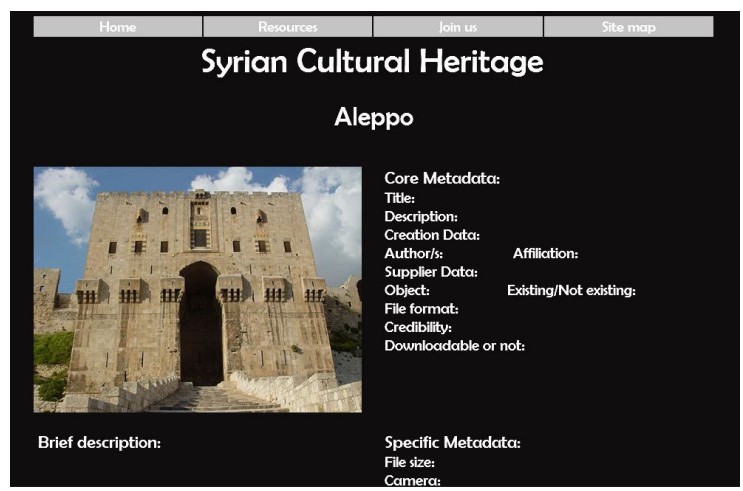

Figure 10. A site example for Aleppo on the planned website

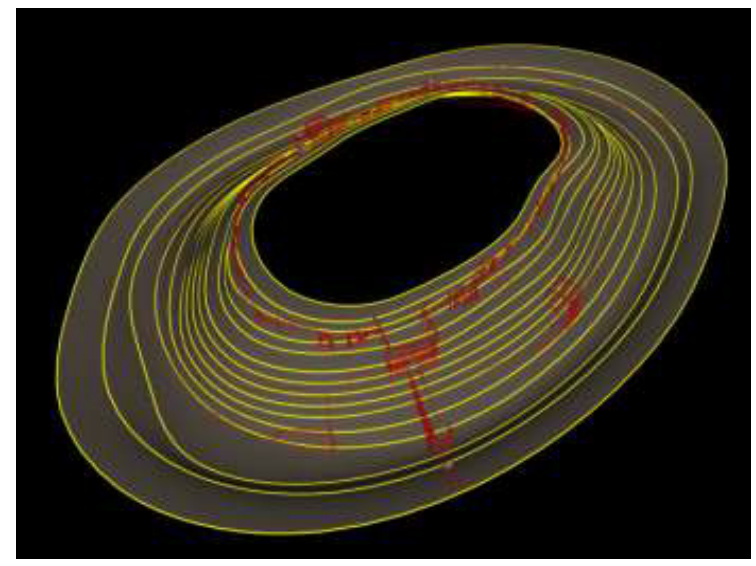

Figure 11. Documenting and modeling the Aleppo citadel with its walls. Courtesy: G. Fangi

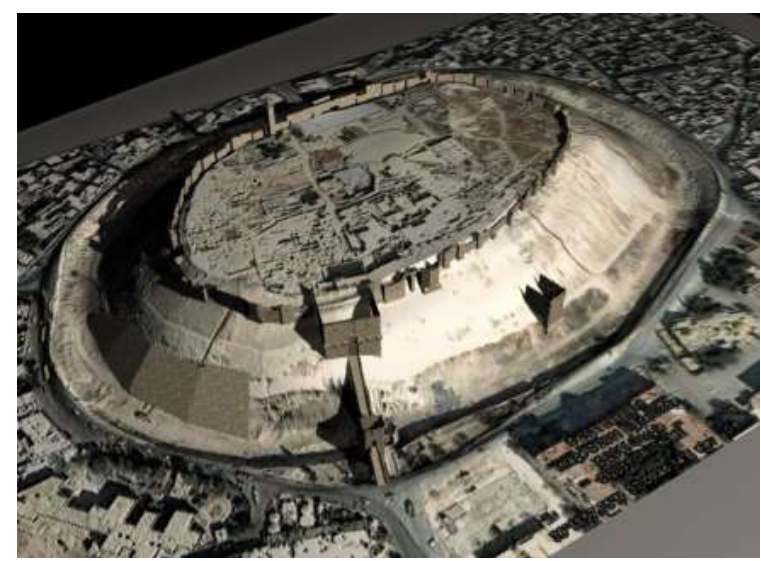

Figure 12. Modeling the Aleppo citadel with its walls. Courtesy: G. Fangi

Old architectural documentation exists of the citadel structures (see, e.g., Fig. 13), for example, made by E. Herzfeld, who also took a panoramic photograph of the site in 1907 (the Metropolitan Museum of Art collection, eeh 1907).
The walls of the citadel were elaborately photographed by Professor G. Fangi from CIPA in 2010. He also carried out the 3D modeling of the site with Dr. W. Wasbeh (Fangi, 2015, Figs. $11,12,14$ and 15). Furthermore, the World Monument Fund has been able to make 3D modelings of the reliefs from the Temple of the Weather God situated in the citadel and dating from the Bronze Age (Kohlmeyer, 2000, B. Burnham's keynote presentation in the 2015 CIPA symposium in Taiwan).

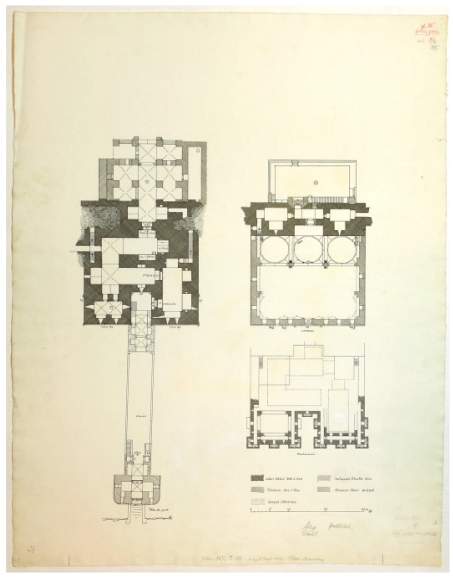

Figure 13. Architectural drawings of the Ayyubid entrance block to the Aleppo citadel by E. Herzfeld (1879-1948)

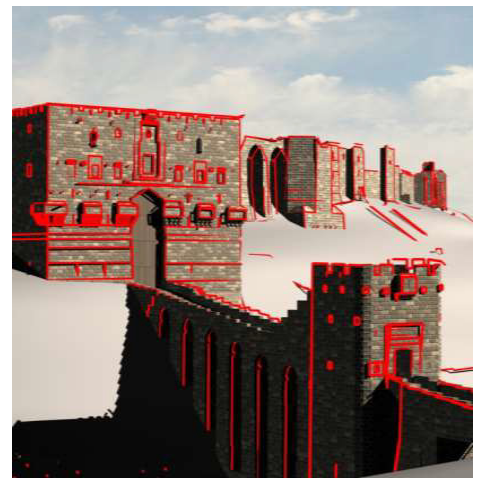

Figure 14. Plotting the architectural entrance to the Aleppo citadel. Courtesy: W. Wasbeh and G. Fangi

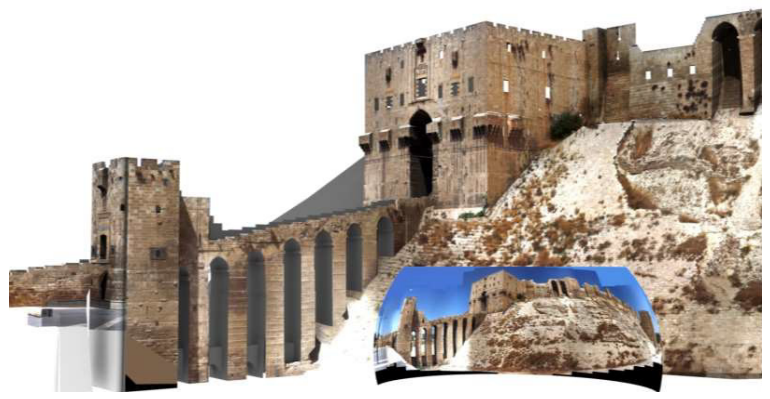

Figure 15. The 3D modeled entrance to the Aleppo citadel. Courtesy: W. Wasbeh and G. Fangi

The Great Mosque of Aleppo has also faced destruction. The mosque was already photographed, for example, by G. Bell (1911) at the beginning of the $20^{\text {th }}$ century (Fig. 16). Before the civil war, beside Professor Fangi (Fangi and Wasbeh, 2013, 
Fangi, 2015), another CIPA member Professor P. Grussenmeyer (2016) had captured valuable data by documenting structures of the Citadel and the Great Mosque. During the first years of the conflict the minaret of the Mosque was destroyed. Based on the captured data the CIPA members with Dr. W. Wasbeh have been able to reconstruct the minaret in $3 \mathrm{D}$ based on the metric data.

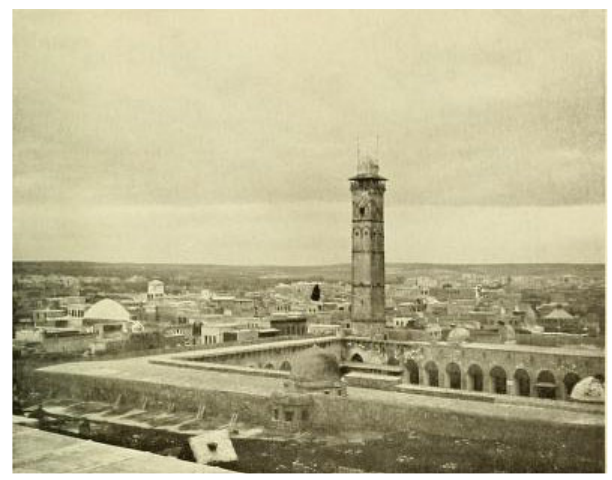

Figure 16. The Great Mosque of Aleppo with its minaret photographed by G. Bell. The minaret was destroyed in 2013. Photo: G. Bell 1909
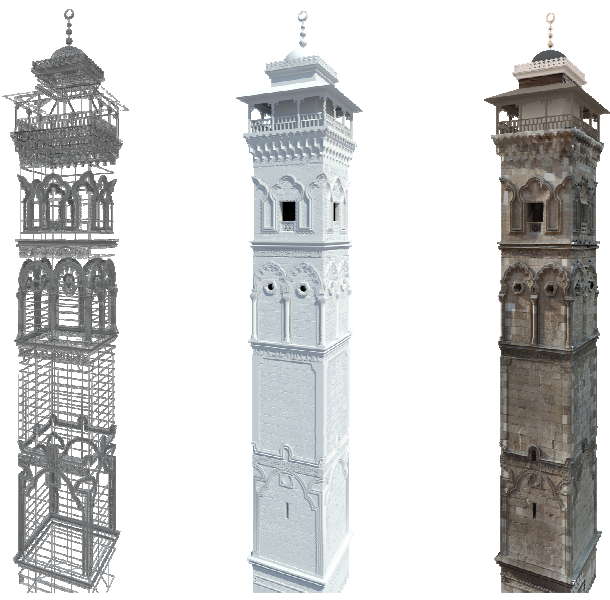

Figure 17. 3D modeling of the destroyed minaret of the Great Mosque of Aleppo: the wire frame, shaded and textured model. Courtesy: W. Wasbeh and G. Fangi

\subsection{Palmyra:}

Temples, the Triumphal Arch, Tower Tombs

Palmyra, known as "the Queen of the Desert" is an oasis city in the Syrian Desert and has been a caravan post on the Silk Road during the Antiquity. The city even expanded to an empire under its queen Zenobia. The heyday of the site dates from the first to the third century AD. (Anadol, 2008). The city and its monuments have been documented by travellers and artists by drawing for hundreds of years. G. Bell also photographed the ruins at the beginning of the $20^{\text {th }}$ century (Fig. 19), and Father A. Poidebard (1934) took aerial photographs of the area in the 1920s and 1930s (Fig. 18). Palmyra is also well known by the CIPA members and has been the target of documentation by its members before the war. Dr. M. Silver has led the SYGIS project under the Museum of Palmyra in 2000-2010 and stored the archaeological finds in the museum. Professor G. Fangi documented ruins with his students in 2010 (Fangi, 2015) and has digitally remodelled several structures (Fangi, 2016).

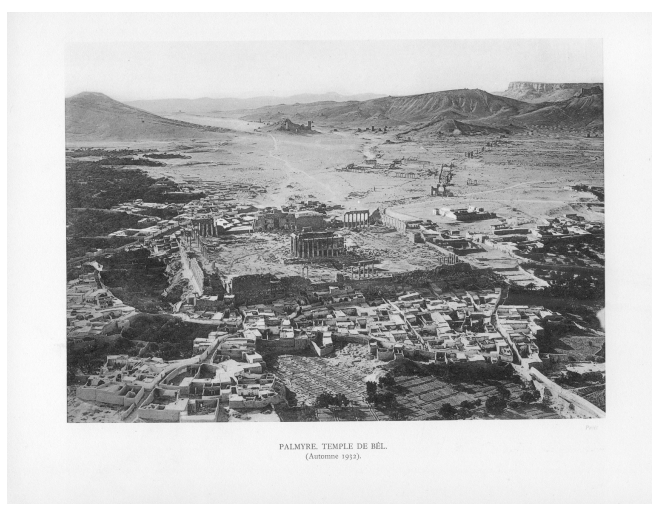

Figure 18. The ruins of Palmyra photographed from the air. In the middle the Temple of Bel surrounded by a large and walled temenos. Photo: A. Poidebard 1932

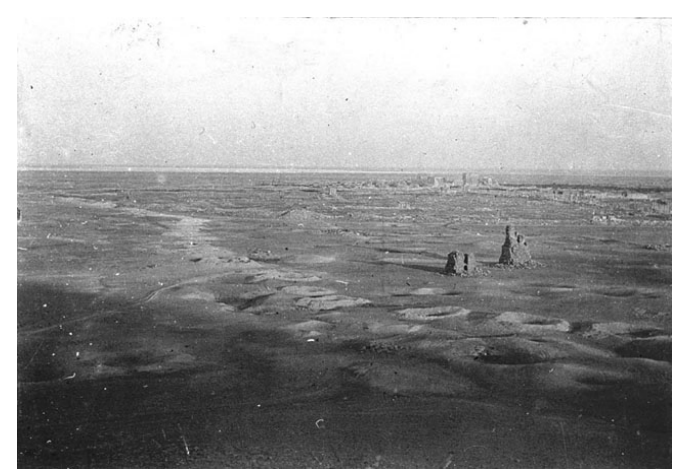

Figure 19. Some ruined tower tombs and looted holes in Palmyra photographed by G. Bell in 1900

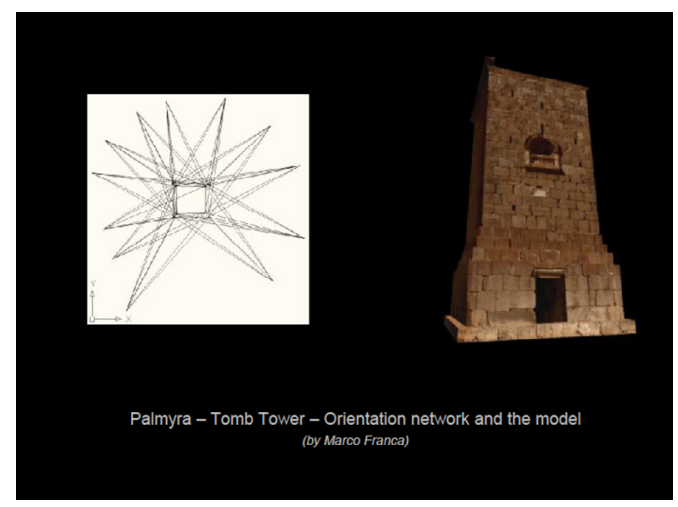

Figure 20. The Tower Tomb of Elahbel modeled by an Italian team led by G. Fangi. Courtesy G. Fangi and M. Franca

When ISIS took over the site in May 2015, the destruction of ancient monuments including the Temple of Bel and the remaining artefacts in the museum started, not to mention the human atrocities for which the monuments became a scene(Lönnqvist, 2015b). Apart from the Temple of Bel, the temple of Baal Shamin, the Triumphal Arch of the colonnaded street and some tower tombs were destroyed by ISIS militants during the occupation in 2015. The citadel of Fakhr al-Minaret in Palmyra has also been damaged during the conflict. (mobile.reuters.com). Based on the documentation by Fangi 
from CIPA and others, such as the New Palmyra project, an open-source project to rebuild Palmyra (www.newpalmyra.org), $3 \mathrm{D}$ reconstructions of the destroyed structures of Palmyra are being produced.

\section{FINAL REMARKS: DATABASE FOR HERITAGE PRESERVATION}

An important step concerning the collection of data testify all the efforts made by the scholars to study and share the importance of the Syrian heritage. The CIPA project, moreover, creates a useful database with which it will be able to support the protection, preservation, restoration and reconstruction strategies.

The data availability and the international importance of CIPA will help all the experts to select the best way to operate on the Syrian historic architecture. The project will allow to operate at a material level, providing information for the treatment of original and historical surfaces, suggesting their protection, their structural consolidation and, when necessary, their partial reconstruction, highlighting the distinctive requirements.

In addition, in order to respect the architectural sites, most characterized culturally and socially, the CIPA project will allow to suggest a reconstruction that does not concern with the substantial and structural aspect of the buildings, but founded on concepts related to virtual and $3 \mathrm{D}$ reconstruction. Evocative phenomena, such like these may, through the use of the data collected, help heritage conservation while safeguarding the cultural value of the original context, avoiding a total reconstruction, hardly compatible with international Charters of Restoration.

As previously mentioned, the project described in this paper has its origins in a proposal made by some of the authors during the CIPA executive board meeting in 2014. The authors will present and elaborate the proposal in the $10^{\text {th }}$ ICAANE in Vienna in April 2016 and in ISPRS 2016 in Prague for the future meetings of CIPA. It is obvious that an enlarged project cannot be supported only by a volunteering action, therefore the project could be the base for fund raising among the CIPA supporters and by joining international competition for research projects.

\section{Acknowledgements}

The authors wish to thank the CIPA executive board for suggestions and the practical help especially for the data provided by Prof. Gabriele Fangi, Dr. Raphaele Héno and Assoc. Prof. Grazia Tucci.

\section{References}

Ali, C., 2016. Abstract for the CIPA workshop on Saving the Heritage of Syria in the 10th ICAANE, 28th April, Vienna, Austria. In: The Abstract Booklet, p. 272.

Anadol, S., 2008. Palmyra - Identity Expressed through Architecture and Art. In: Jebel Bishri in Context: Introduction to the Archaeological Studies and the Neighbourhood of Jebel Bishri in Central Syria, Proceedings of a Nordic Research Training Seminar in Syria, May 2004, ed. Lönnqvist, M., BAR International Series 1817, Archaeopress, Oxford, pp. 59-72.

Ardissone, P. and Rinaudo, F., 2005. A GIS for the Management of Historical and Archaeological Data. In: Proceedings of CIPA 2005, XX International Symposium, 26
September-01 October, 2005, Torino, Italy http://cipa.icomos.org/fileadmin/template/doc/TURIN/643.pdf.

Bell, G.L., 1911. Amurath to Amurath. William Heinemann, London.

Fangi, G., 2015. Documentation of Some Cultural Heritage Emergencies in Syria in August 2010 by Spherical Photogrammetry. In: ISPRS Annals, Vol. II-5/w3, pp. 401-408.

Fangi, G., 2016. Abstracts for the CIPA workshop on Saving the Heritage of Syria in the 10th ICAANE, 28th April, Vienna, Austria. In: The Abstract Booklet, p. 269.

Fangi, G. and Wasbeh, W., 2013. The Destroyed Minaret of the Ummayad Mosque of Aleppo, the Survey of the Original State. European Scientific Journal, December 2013, Special edition, Vol. 4, pp. 403-409.

Grussemmeyer, P., 2016. Abstract for the CIPA workshop on Saving the Heritage of Syria in the 10th ICAANE, 28th April, Vienna, Austria. In: The Abstract Booklet, p. 271.

Kohlmeyer, K., 2000. Der Tempel des Wettergottes von Aleppo. Gerda Henkel Vorlesung.

Le Tensorer, J.M., Le Tensorer, H., Martini, P., Falkenstein, V. von, Schmidt, P., Villalain, J.J., 2015. The Oldowans Site Ain al Fil (El Kowm, Syria) and the first humans of the Syrian Desert. Le site Oldowayen d'Ain al Fil (El Kowm, Syrie) et les premiers homes du Désert Syrien. L'Anthropologie, Vol. 119, pp. 581-594.

Lönnqvist, M., 2000. Between Nomadism and Sedentism: Amorites from the Perspective of Contextual Archaeology. Juutiprint, Helsinki.

Lönnqvist, M., 2015a. After the Fall of Palmyra the Peril of the Ruins is Looming. In: CIPA Newsletter, No. 6, May 2015.

Lönnqvist, M., 2015b. The Destruction of Cultural Memory in Palmyra. In: CIPA Newsletter, No. 7, October 2015.

Lönnqvist, M. and Stefanakis, E., 2009. GIScience in Archaeology: Ancient Human Traces in Automated Space. The Manual of Geographic Information Systems, ed. by M. Madden, American Society of Photogrammetry and Remote Sensing, Bethesda, Maryland, pp. 1221-1259.

Moore, A., Hillman, G.C., Legge, A.J., 2000. Village on the Euphrates: From Foraging to Farming at Abu Hureyra. Oxford University Press, Oxford.

Poidebard, A. (1934) La Trace de Rome dans le Désert de Syrie. Le Limes de Trajan a la conquête arabe. Bibliotheque Archéologique et Historique. Tome XVIII. Paul Geuthner, Paris.

Rinaudo, F. and Silver, M., 2016. Abstracts for the CIPA workshop on Saving the Heritage of Syria in the 10th ICAANE, 28th April, Vienna, Austria. In: The Abstract Booklet, p. 268.

Schniedewind, W.M. and Hunt, J.H., 2007. A Primer on Ugaritic: Language, Culture and Literature. Cambridge University Press, Cambridge.

Vita-Finzi, C., 1978. Archaeological Sites in their Setting. Ancient Peoples and Places. Thames \& Hudson, London. 